\title{
Spleen Preserving Treatment of a Ruptured Splenic Artery Aneurysm (SAA) in Emergency Setting: A Case Report and Review of the Literature
}

\author{
Matteo Giardini*, Folco Solimene, Georgios Peros and Sotirios Ntaoulas \\ Department of Surgery, Cantonal Hospital of Winterthur, Winterthur, Switzerland
}

*Corresponding author: Matteo Giardini, Folco Solimene, Department of Surgery, Cantonal Hospital of Winterthur,

Winterthur, Switzerland

\begin{tabular}{|c|c|}
\hline ARTICLE INFO & ABSTRACT \\
\hline $\begin{array}{l}\text { Received: 幽 September 23, } 2021 \\
\text { Published: } \text { October } 04,2021\end{array}$ & $\begin{array}{l}\text { Objective: Splenic artery aneurysm exclusion from blood flow while preserving the } \\
\text { spleen has been described in the elective setting. In emergency setting, only one case } \\
\text { report of spleen preserving open aneurysm resection has been found. We can confirm } \\
\text { the safety of the procedure. }\end{array}$ \\
\hline $\begin{array}{l}\text { Citation: Matteo Giardini, Folco Solimene, } \\
\text { ieorgios Peros and Sotirios Ntaoulas. }\end{array}$ & $\begin{array}{l}\text { Design: We present the case of a male patient with a ruptured SAA and } \\
\text { hemodynamical instability. }\end{array}$ \\
\hline $\begin{array}{l}\text { Spleen Preserving Treatment of a Rup- } \\
\text { ured Splenic Artery Aneurysm (SAA) in } \\
\text { Emergency Setting: A Case Report and Re- }\end{array}$ & $\begin{array}{l}\text { Results: Open surgical treatment of ruptured SAA through aneurysm resection was } \\
\text { successful and the spleen could be preserved with sufficient perfusion. The procedure } \\
\text { was safe even with a hemodynamical instable patient. }\end{array}$ \\
\hline Res 39(2)-2021. BJSTR. MS.ID.006266. & $\begin{array}{l}\text { Conclusions: Complications after splenectomy are well described. We recommend } \\
\text { a spleen preserving open surgical treatment of ruptured SAA even with hemodynamical } \\
\text { instability. }\end{array}$ \\
\hline
\end{tabular}

\section{Introduction}

Visceral artery aneurysms represent a rather rare disease with documented incidence of $0,1-0,2 \%$. The actual incidence is underestimated, since most aneurysms remain asymptomatic [1]. Of all abdominal vessels, the splenic artery is the third most common affected branch after aortic and iliac arteries [2]. Of the visceral arteries, the splenic artery is the most common affected (60-70\%), followed by the hepatic artery (20\%) and the celiac/ mesenteric arteries (10\%) [3].

Most SAA affect the distal third of the artery and are typically solitary and saccular shaped lesions. In one-third of SAA cases concomitant aneurysms were found at other localizations [4]. Predisposing factors for aneurysm are the well-known cardiovascular risk factors like atherosclerosis (32\%), medial degeneration (24\%) and inflammatory diseases (10\%); previous

abdominal trauma was often stated (22\%). Less common are high blood flow conditions (e.g., pregnancy, portal hypertension) or fibroconnective tissue diseases. The diagnosis of SAA is made either after rupture or incidentally [4]. After rupture, a spontaneous stabilization can occur if the bursa omentalis temporarily contains the bleeding through compression. The natural consequence, if untreated, is the haemorrhagic shock.

Management of SAA depends on the timing of initial diagnosis. Acute ruptured aneurysms show mortality rates of $10-70 \%$ and are therefore a surgical emergency [3]. Incidental aneurysms with diameters $<2.5 \mathrm{~cm}$ rarely rupture spontaneously, as shown by the Mayo Clinic and the Cleveland Clinic [5]. Size $>3 \mathrm{~cm}$ as well as symptomatic SAA and all pseudoaneurysms should be treated urgently [6]. In contrast to real aneurysms, only specific wall layers 
are affected in pseudoaneurysms. Abdominal pseudoaneurysms are often consequence of trauma or iatrogenic injury with faster enlargement and higher rupture rates.

The aim of the treatment is to exclude the aneurysmatic sac from blood flow without compromising the distal perfusion. This can be accomplished with a surgical or endovascular approach [2]. Treatment of asymptomatic aneurysm should be performed in an elective setting and an endovascular treatment should be discussed. Depending on end-organ perfusion but also on the size and location of the aneurysm along the splenic artery, the need for splenectomy must be evaluated. In most cases end-organ perfusion can be guaranteed by collateral arteries and other perfusion sources (i.e., Aa. gastricae breves, Aa. caudae pancreatis), therefore the need for this procedure remains an exception [7].

\section{Case}

We present the case of a 40-year-old male patient transferred from a regional hospital. At first contact severe, acute, left abdominal pain since a few hours were stated. Previous illnesses or surgical treatments were denied. His mother died due to a ruptured intracranial aneurysm, no cases of connective tissue diseases were known in the family. He had nicotine abuse as a risk-factor. Initially the patient was hemodynamically stable (BP 138/100mmHg, P $80 / \mathrm{min}$, SO2 $100 \%$, T $36.8^{\circ} \mathrm{C}$ ) with signs of peritonitis to the left abdomen. Sonography showed excessive free fluid. A CT scan identified a ruptured aneurysm of the splenic artery (Figure 1) and the transfer to the shock room followed.

No other bleeding sites or aneurysms could be identified. Initially haemoglobin $(\mathrm{Hb})$ was $15 \mathrm{~g} / \mathrm{l}$, after one hour it dropped to $13 \mathrm{~g} / \mathrm{l} .1 \mathrm{~g}$ Tranexamic acid (TXA) was injected. Upon arrival in the shock room GCS was 15 and the patient was hemodynamically stable. Hb was $11.7 \mathrm{~g} / \mathrm{l}$, INR 1.1, thrombocytes $215 \mathrm{G} / \mathrm{l}$ and fibrinogen $2.1 \mathrm{~g} / \mathrm{l}$. An interventional management was initially discussed. Due to progressive hemodynamical instability and no response to fluid therapy (BP 100/60mmHg, P 105/min) we performed an emergency median laparotomy because of hemorrhagic shock. The bursa omentalis was opened, about $1.5 \mathrm{~L}$ of blood was evacuated (total blood loss $2.5 \mathrm{~L}$ ), the splenic artery was identified and clipped (Figure 2).

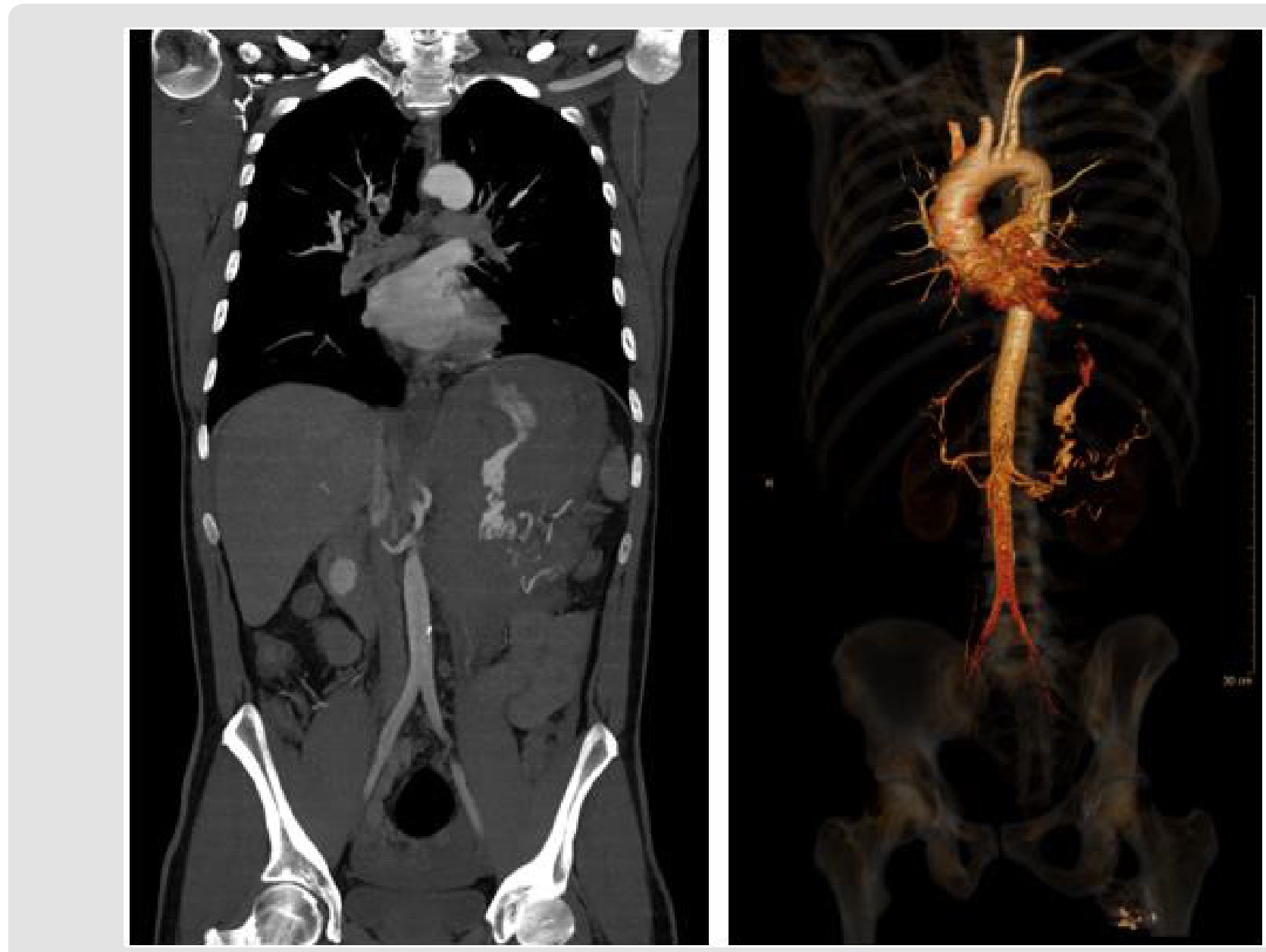

Figure 1: CT-Scan: Coronary MIP-Sequence and 3D-Reconstruction. 


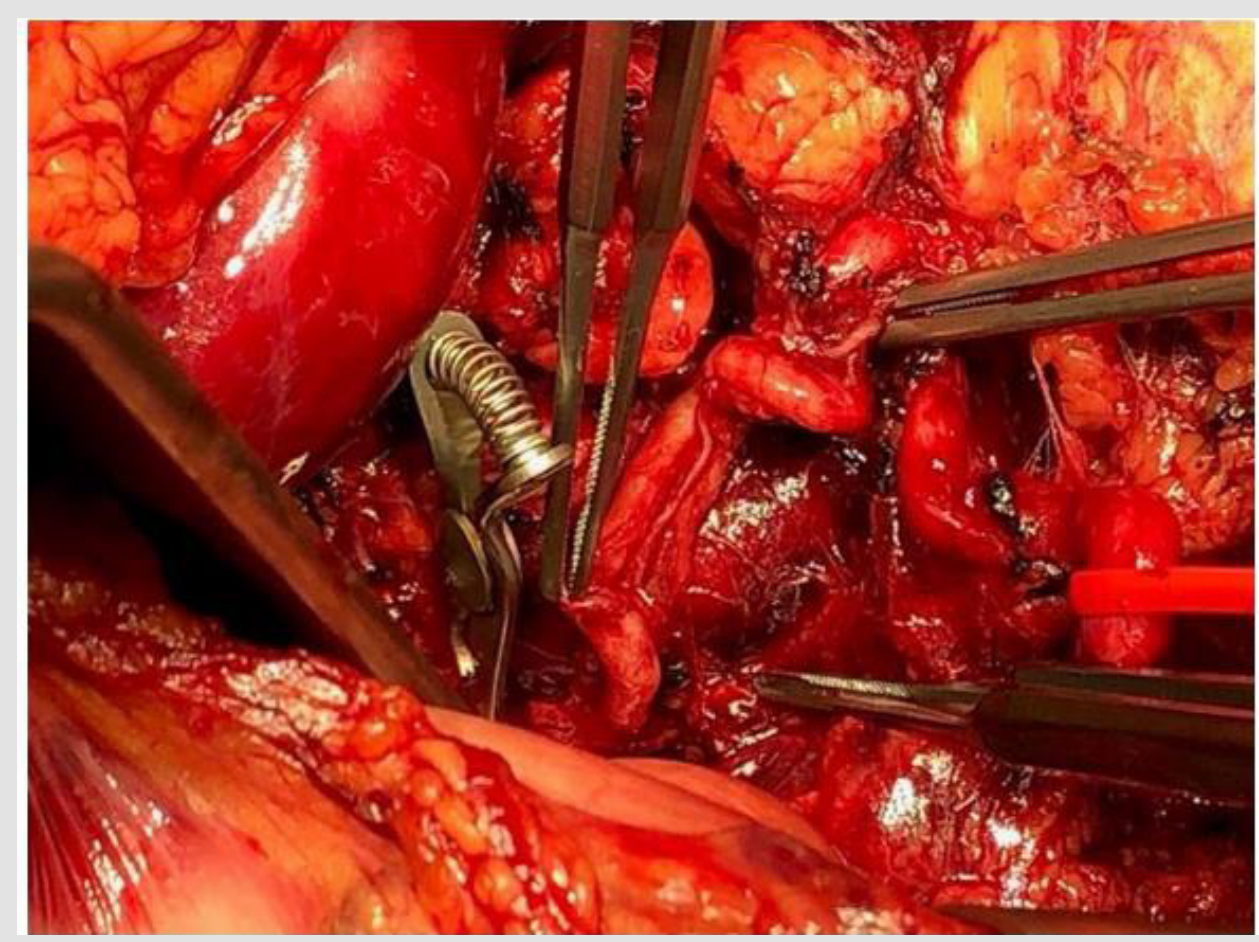

Figure 2: Intraoperative situs: clamped splenic artery.

As the active bleeding reduced, the aneurysm sac was identified After controlling of residual bleeding, the spleen did not show any ischemic sufferance. An accessory arterial branch guaranteed the splenic perfusion, and we performed a spleen preserving aneurysm resection. The aneurysmatic lesion (length $8.5 \mathrm{~cm}$ ) was removed. A drain was inserted above the pancreas tail. Before closure, there was no sign of hypoperfusion of the spleen. Intraoperative transfusion of two red cell concentrates $(600 \mathrm{ml})$ and $600 \mathrm{ml}$ of own blood through Cell Saver followed. The minimal postoperative $\mathrm{Hb}$ after transfusions was $9.9 \mathrm{~g} / \mathrm{l}$.

The postoperative monitoring in ICU was uneventful. Prophylactic broad-spectrum antibiotic was stopped after 72 hours. A POPF Grad A (postoperative pancreas fistula, biochemical leak) was detected. The drain was removed on POD 7 after a CT scan, the spleen showed normal perfusion. The discharge was on POD 8. The histological aetiology of the lesion was a chronic arteriosclerosis. The 30-days follow-up showed an asymptomatic Patient with normalized Hb. A brain MRI excluded concomitant intracranial aneurysms. A CT scan 3 months after surgery showed a normal splenic perfusion with pancreo splenic and gastro-splenic collaterals. A genetic analysis to rule out genetic connective tissue disease was done. No pathological findings were reported.

\section{Discussion}

Ruptured SAA represent a surgical emergency and show mortality rates of $10-70 \%$ [8]. The treatment should be performed open surgically whenever possible [4,8]. Endovascular approaches in the emergency setting have shown fewer desirable outcomes, including the risk of postembolization syndrome and incomplete aneurysm exclusion [3,8]. In elective setting, laparoscopic or endovascular approaches are preferred [6]. A retrospective analysis of a series of 94 patients undergoing aneurysm repair showed morbidity and mortality rates in open approach $(n=74)$ respectively at $9.4 \%$ and $1.3 \%$. The endovascular approach $(n=20)$ showed morbidity rates of $10 \%$ with no mortality [9]. We report a spleen preserving open aneurysm resection as surgical treatment of ruptured SAA in haemorrhagic shock since the spleen did not show any ischemic sufferance. Spleen preüserving management of SAA is well described in elective settings, in emergency settings just by endovascular treatment. We only found one similar case report (in English) [10]. We confirm that this procedure can be performed in open surgical emergency treatment of ruptured SAA. $80 \%$ of patients presenting with aneurysms of the splenic artery are over 50 years old [5]. The prevalence of splenic artery aneurysm in patients with liver cirrhosis and portal hypertension is $7-20 \%$ [4]. Concomitant aneurysms, which can be found in one third of the patients with SAA [4], should be excluded through brain MRI and thoracic-abdominal CT scan. A genetic testing to exclude a connective tissue disease is suggested.

We confirm that the clinical guidelines should be followed in decision making. Open surgery remains the gold standard in the treatment of ruptured SAA and a spleen-preserving management should always be pursued. 


\section{Conflict of Interest}

No conflict of interest with any institution/organization.

\section{References}

1. Cordova AC, Sumpio BE (2013) Visceral Artery Aneurysms and Pseudoaneurysms-Should They All be Managed by Endovascular Techniques? Ann Vasc Dis 6(4): 687-693.

2. Hogendoorn W, Lavida A, Myriam Hunink MG, Moll FL, Geroulakos G, et al. (2014) Open repair, endovascular repair, and conservative management of true splenic artery aneurysms. Vol. 60, Journal of Vascular Surgery. Mosby Inc: 1667-1676.e1.

3. Stanley JC, Wakefield TW, Graham LM, Whitehouse WMJ, Zelenock GB et al. (1986) Clinical importance and management of splanchnic artery aneurysms. J Vasc Surg 3(5): 836-840.

4. Berceli SA (2005) Hepatic and splenic artery aneurysms. Semin Vasc Surg 18(4): 196-201.

ISSN: 2574-1241

DOI: $10.26717 /$ BJSTR.2021.39.006266

Matteo Giardini. Biomed J Sci \& Tech Res

(C) (P) This work is licensed under Creative

Submission Link: https://biomedres.us/submit-manuscript.php
5. Abbas MA, Stone WM, Fowl RJ, Gloviczki P, Oldenburg WA, et al. (2002) Splenic artery aneurysms: two decades experience at Mayo clinic. Ann Vasc Surg 16(4): 442-449.

6. Chaer RA, Abularrage CJ, Coleman DM, Eslami MH, Kashyap VS, et al. (2020) The Society for Vascular Surgery clinical practice guidelines on the management of visceral aneurysms. J Vasc Surg 72(1S): 3S-39S.

7. Messina LM, Shanley CJ (1997) Visceral artery aneurysms. Surg Clin North Am 77(2): 425-442.

8. Ferrero E, Viazzo A, Ferri M, Robaldo A, Piazza S, et al. (2011) Management and urgent repair of ruptured visceral artery aneurysms. Ann Vasc Surg 25(7): 981.e7-981.e11.

9. Marone EM, Mascia D, Kahlberg A, Brioschi C, Tshomba Y, et al. (2011) Is open repair still the gold standard in visceral artery aneurysm management? Ann Vasc Surg 25(7): 936-946.

10. Lo WL, Mok KL (2015) Ruptured splenic artery aneurysm detected by emergency ultrasound-a case report. Crit Ultrasound J 7(1): 7-10.

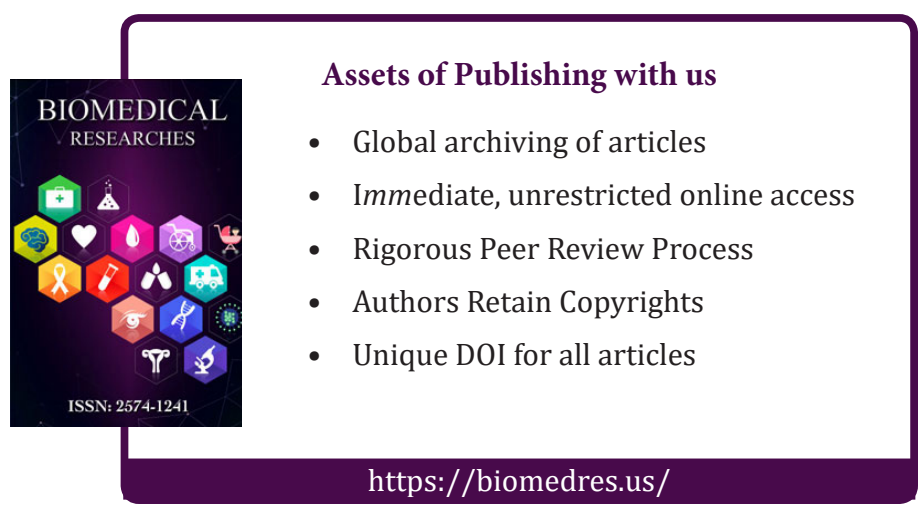

